\title{
COMPARING CARBON EMISSIONS STANDARDS IN SUSTAINABLE BUILDING RATING SYSTEMS (SBRS)
}

\author{
Heba Abdel Salam Youssef ${ }^{1}$, Tarek Saad El-Hinnawy ${ }^{2}$, Mahmoud Fathy Ahmed ${ }^{3}$ \\ ${ }^{1}$ Assistant Lecturer, Department of Architecture, Pyramids Higher Institute of Engineering and Technology \\ ${ }^{2}$ Emeritus Professor, Department of Architecture, Faculty of Engineering, Shoubra, Benha University \\ ${ }^{3}$ Lecturers, Department of Architectural Engineering, Faculty of Engineering in Shubra, Benha University \\ Principal Investigator email: enghebayousef19@gmail .com \\ Received :30 Nov. 2021 Accepted:28 Dec. 2021
}

\begin{abstract}
:
The trend towards protecting the environment from the negative impact of carbon emissions from buildings and preserving resources led to the issuance of many systems for assessing sustainability of building, many of them at the international level and others at the regional and local levels, but when addressing the study and audit of those systems, It is found find that most of them make the criterion for reducing carbon emissions sub-points included in the context of other key elements of the evaluation as a sub-assessment point, Although it represents an important goal for the vision of sustainable development in general and treatment of environmental changes in particular, Therefore the research will discuss the negative role of buildings on the environment, and present And an analysis of the assessment systems for sustainable buildings and their main assessment elements, and then analysis and comparison between them to extract carbon emissions assessment points and to know if any of them can give an integrated system for evaluating emissions of carbon as a basic criterion for evaluation. The research concludes that the Australian system GREEN STAR can be applied as an indicator to assess emissions in buildings, and as a comprehensive evaluation system for all the basic elements of the basic development goals clearly.
\end{abstract}

Keywords: Zero carbon, Sustainable Building Rating Systems, Sustainable, Zero emissions .

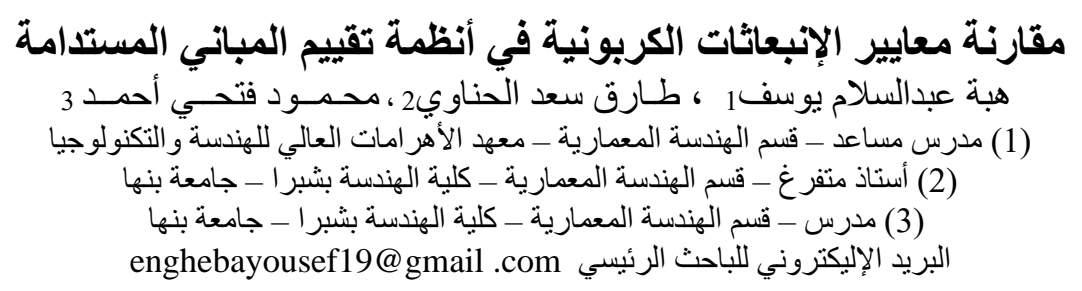




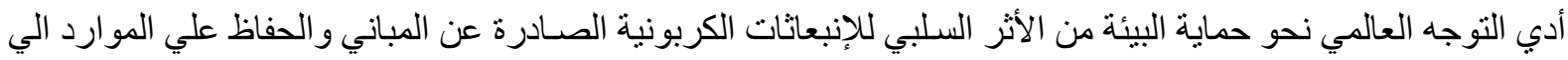

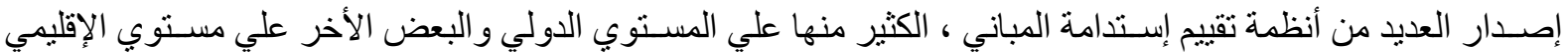

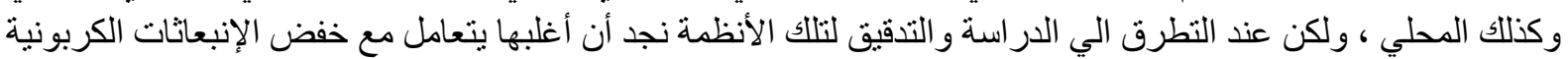

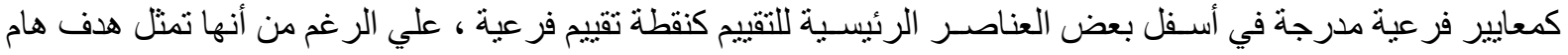

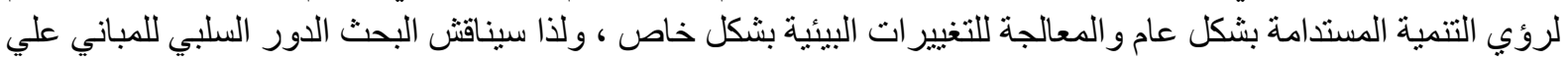

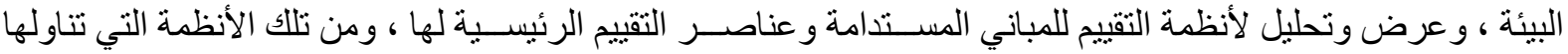

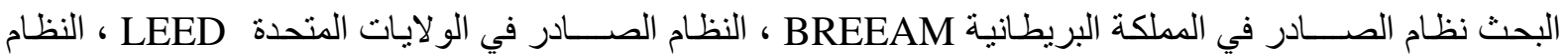

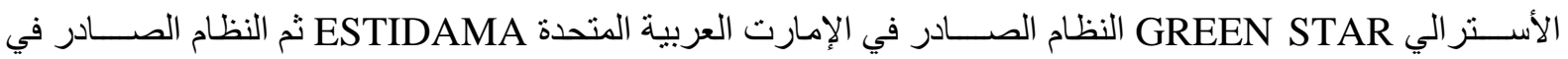

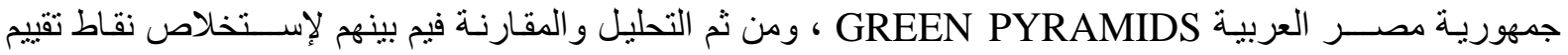

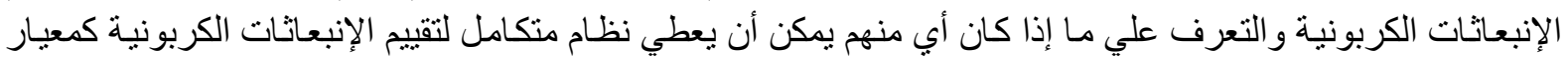

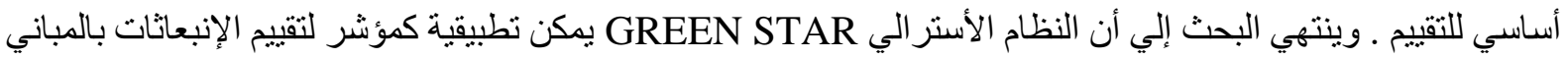

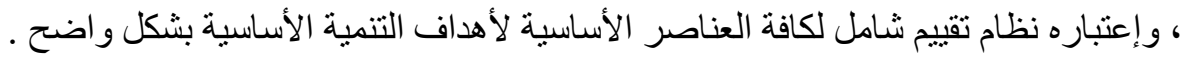
الكلمات المفتاحية : صفرية الكربون ـ أنظمة تقييم إستدامة المباني ـ الإستدامة ـ صافي إنبعانات .

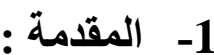

يعتبر الإحتباس الحراري أهم المشاكل البيئية في الأونة الأخيرة ، وذلك نتيجة إمتصاص الأشعة وإحتباسها بو اسطة

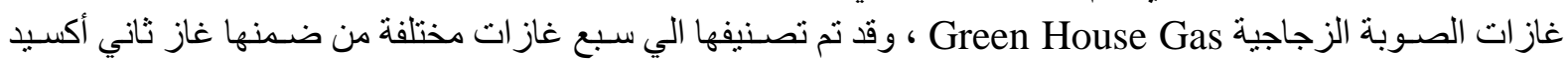

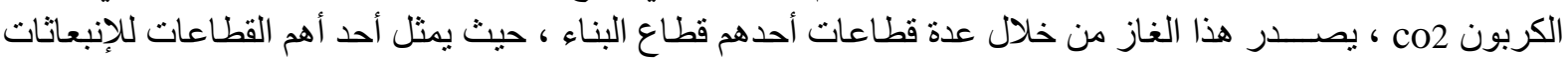

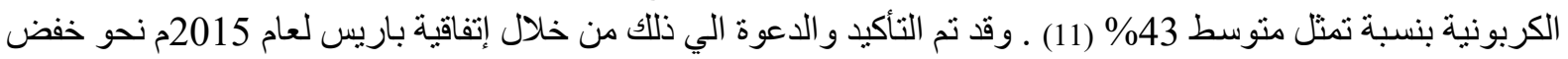

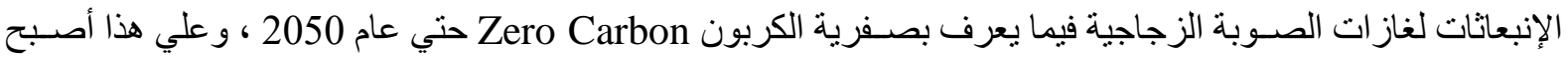

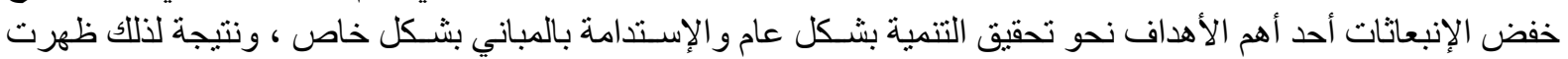

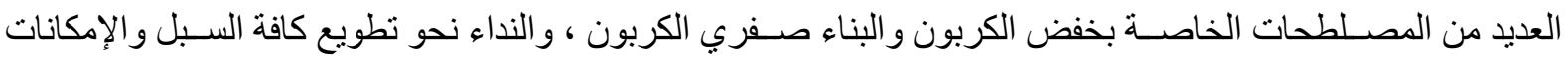

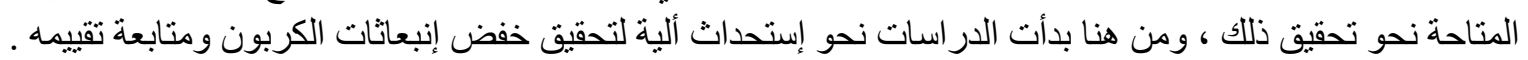

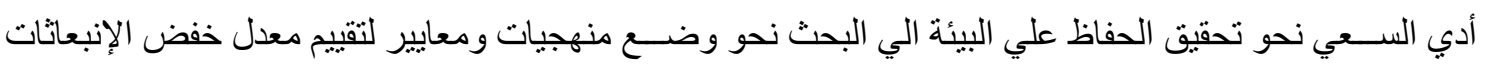

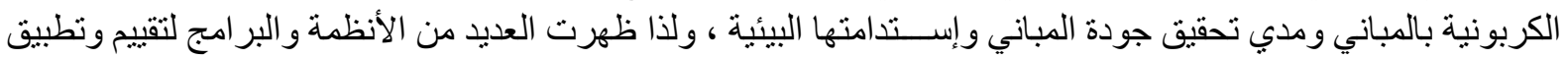

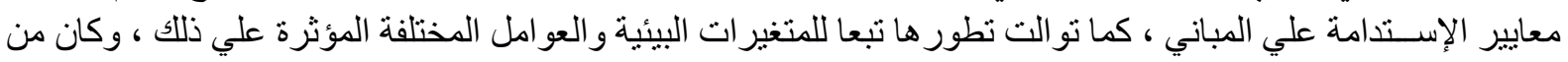

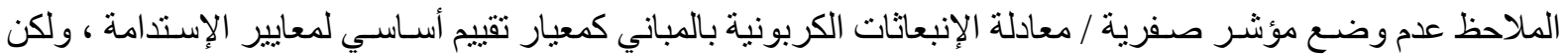

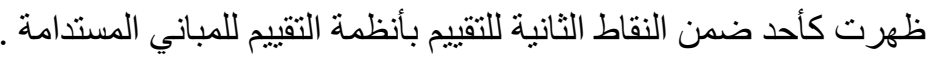

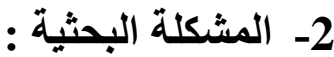

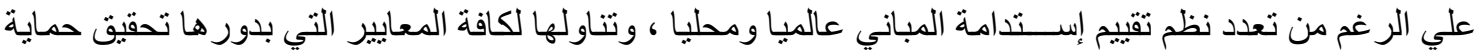

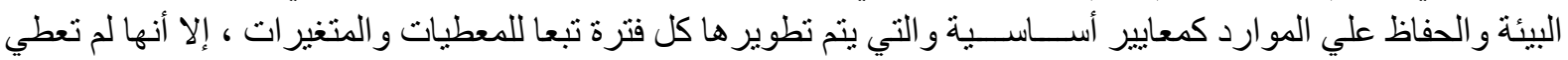

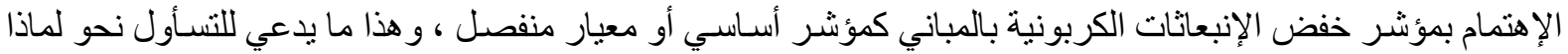

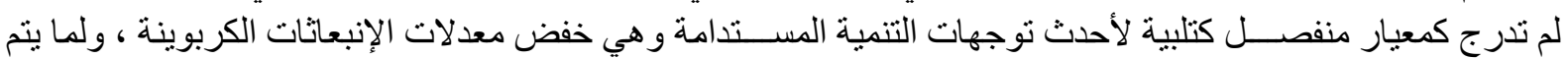

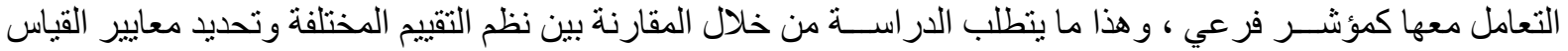

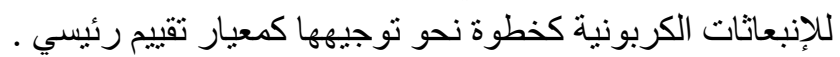


يهدف البحث الي در اسـة بعض نظم التقييم للتعرف علي عناصر التقييم الأساسية لكل نظام ، ومن ثم إجر اء مقارنة

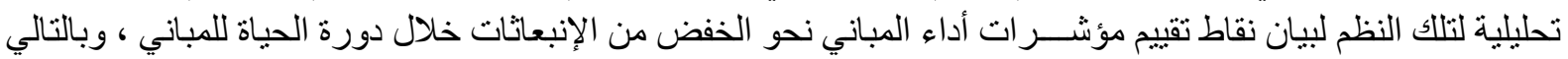

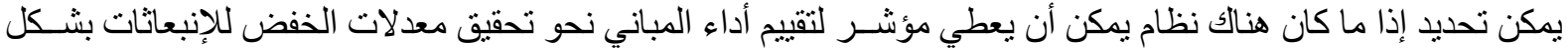

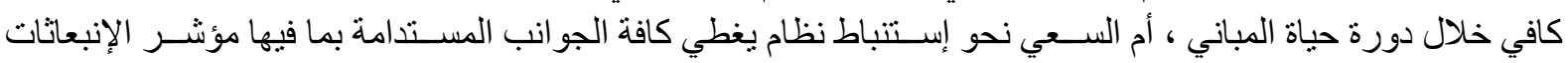

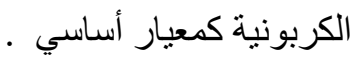

\section{4- المباني صفرية الكريون ZCB) Zero Carbon Building):}

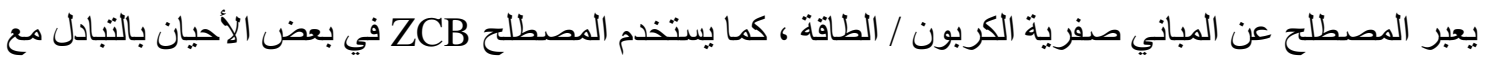

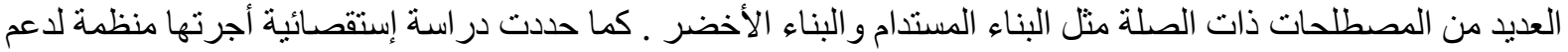

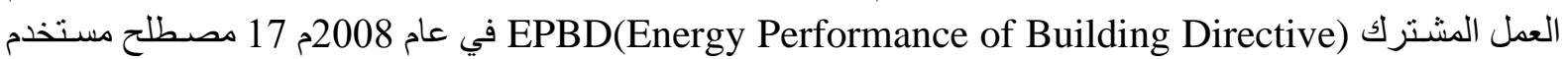
لوصف المباني منخفضة الكربون و الطاقة علي مستوي العالم ، ثم تم تز ايد ذلك في تقرير العمل التالي للمنظمة ، و الذي قدام

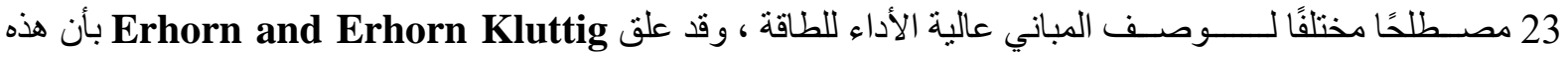

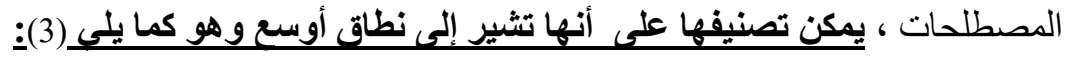
• إستهلاك منخفض للطاقة ( منشـأ منخفض الطاقة ، موفر للطاقة ، طاقة منخفض للغاية ، طاقة بدون تدفئة ، بدون طاقة

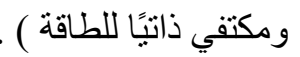

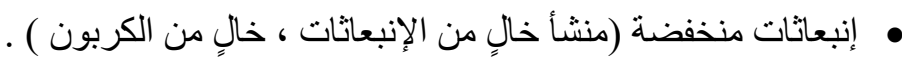

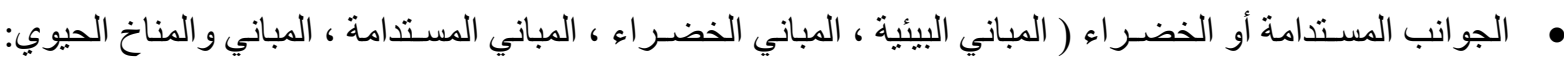
المبني النشط أو الفعال ) . (2)

حدد Riedy. ET. AL (8) لتعريف المباني ذات الإنبعاثات الصــفرية العديد من المصــطلحات المماثلة في الإســتخدام

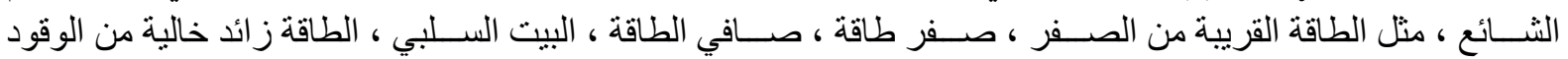

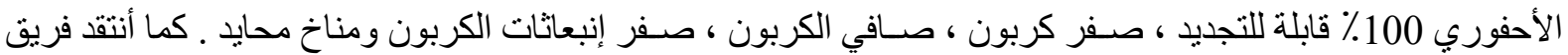

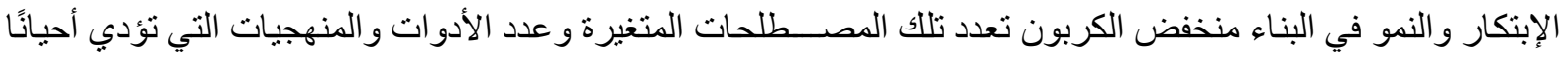

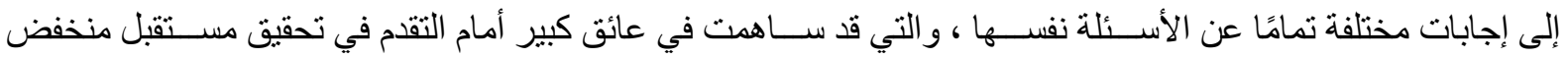

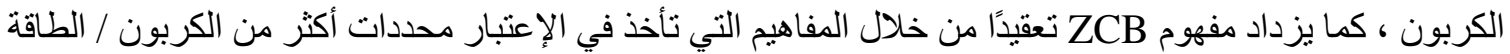

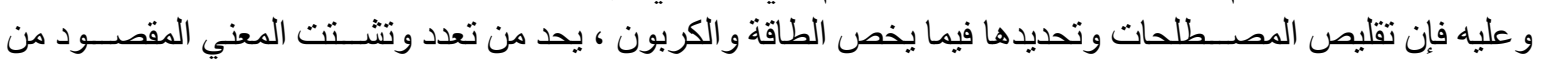
ZCB ، ويمكن تصنيفها بإستخدام بعدين أساسين الطاقة والكربون تبعا للجانب الوصفي أو الأنشطة ، وسيتت عرضها كما

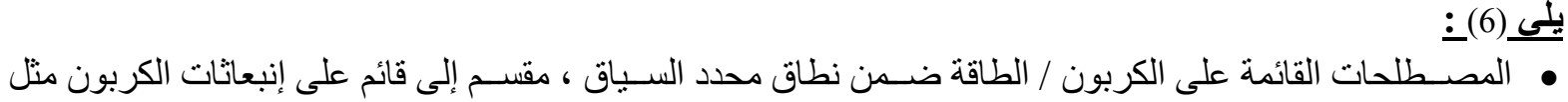

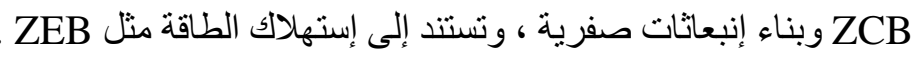

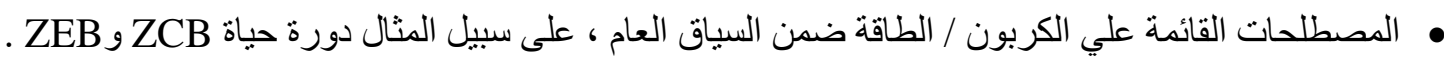

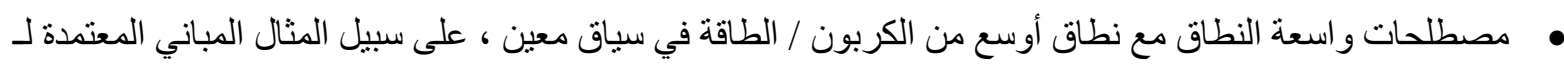

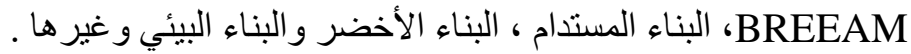

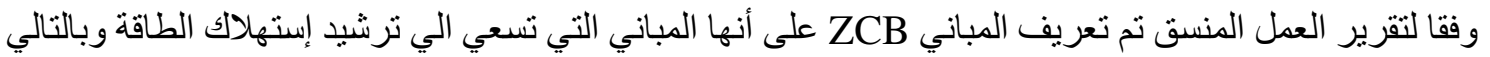

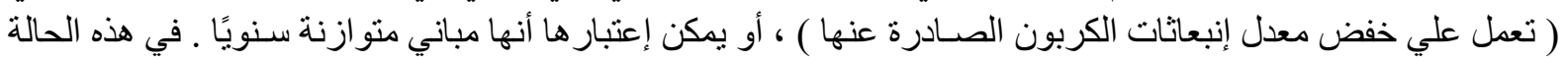

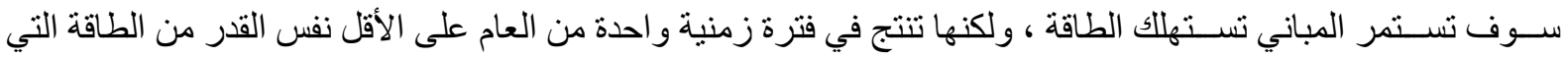
تحتاجها خلال العام بأكمله .

\section{5- مصادر الإنبعاثات الكربونية خلال دورة الحياة للمباني :}

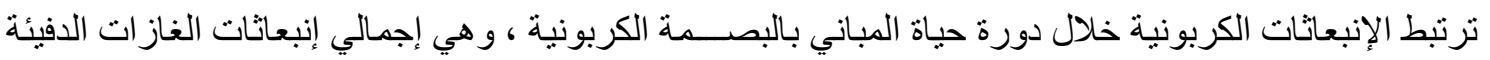

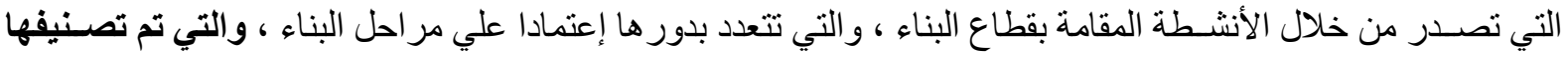
الي ثلاث مراحل وسيتم عرضها كالتالي : 
مرحلة الإنتاج The production stage: نتـــل إنبعاثات الكربون الناتجة من عملية إنتاج مواد البناء ، بما في الإني

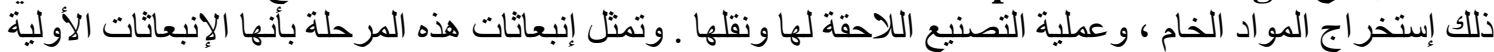

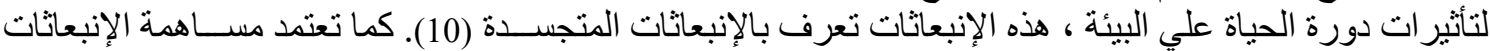

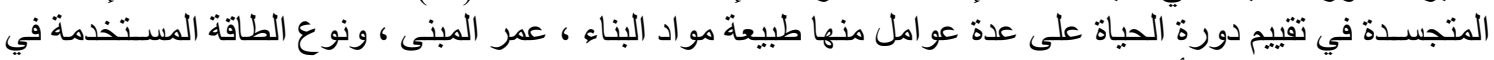

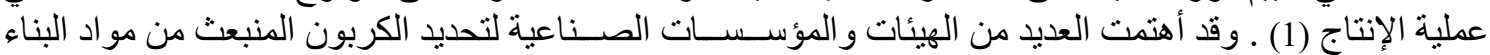

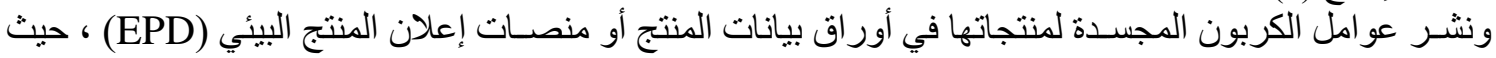

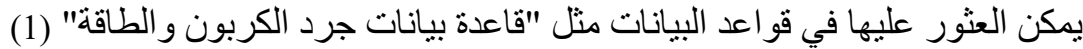

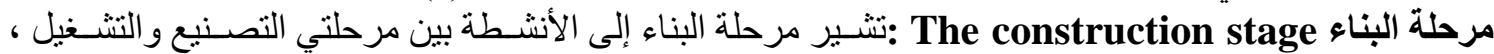

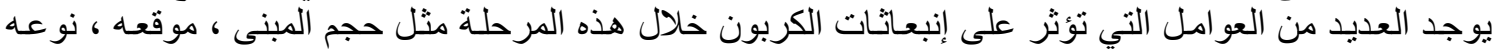

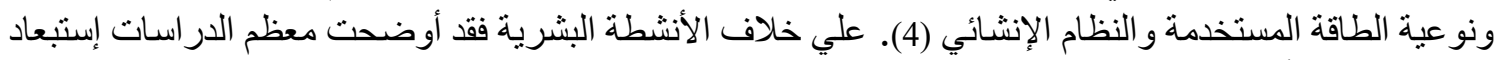

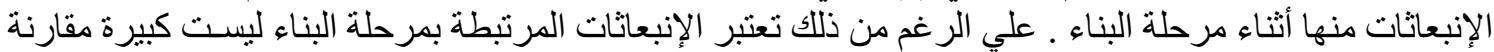

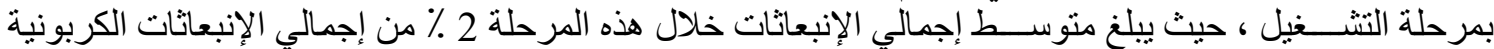

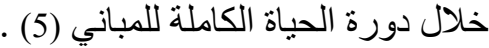

تـ- مرحلة التشغيل The Operation stage : تمثل مرحلة التشغيل بشكل عام الأنشطة للمستخدمين ومدي الإعتماد

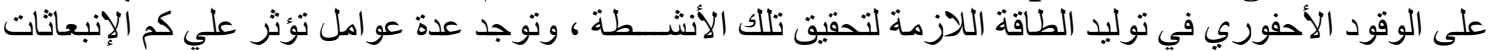

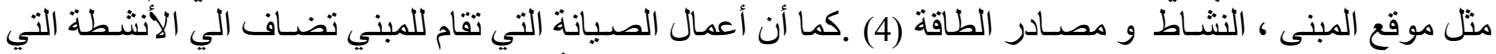

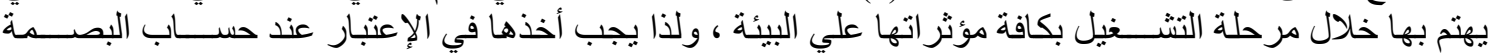

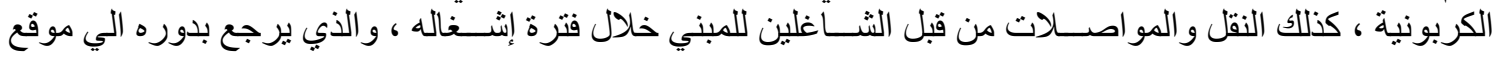
المبني ومدي نوفير و سائل النقل للثناغلين (5).

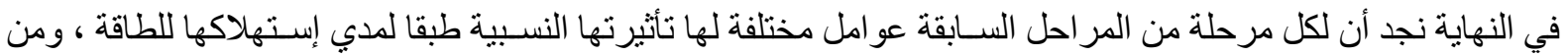

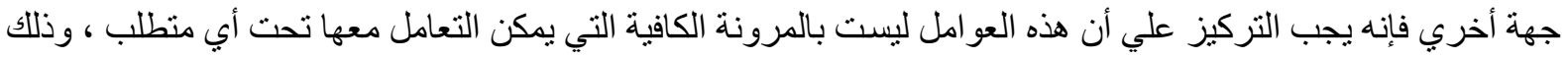

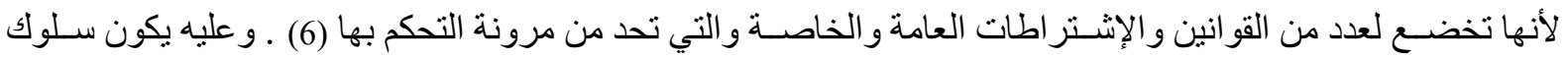

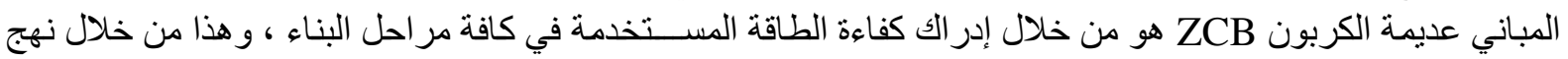

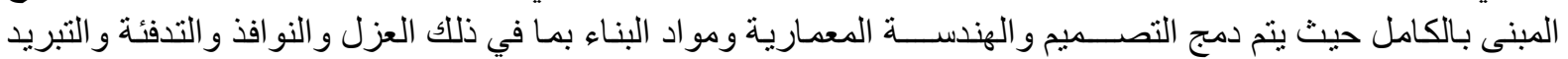
و الكهرباء ومعدات تبادل الهو اء لتقليل إستخدام الطاقة قدر الإمكان وبالتالي الإنبعاثات الكربونية .

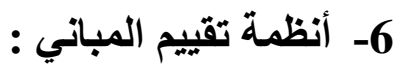

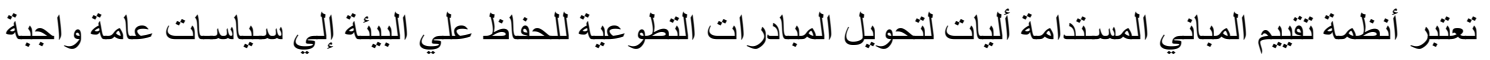

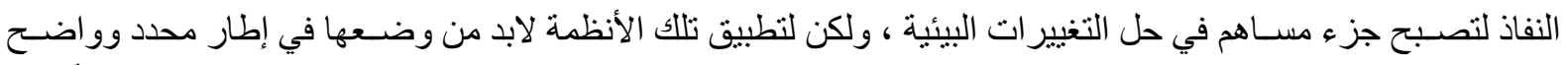

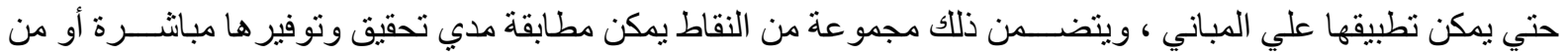

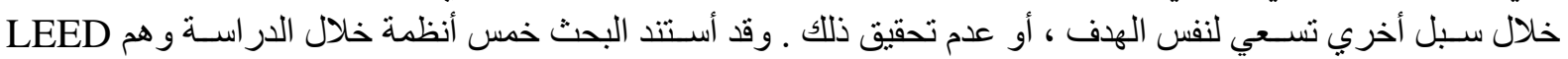

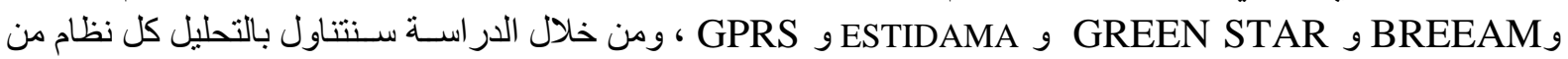

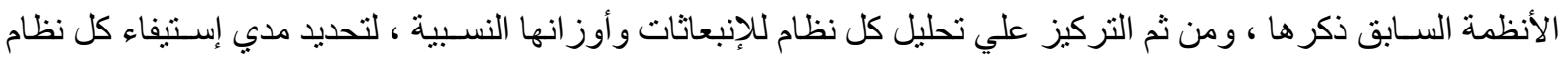

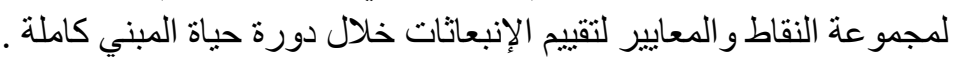

\section{7- التحليل الكمي لمعايير أنظمة تقييم المباني محل الاراسة :}

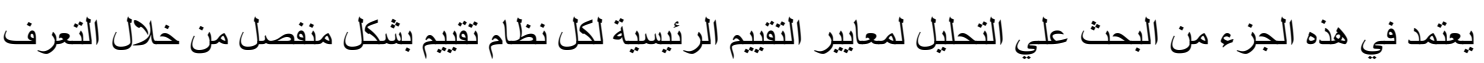

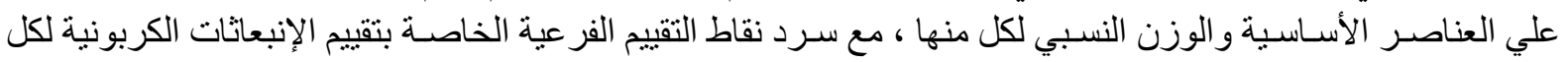

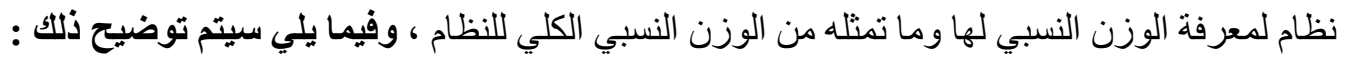

\section{أـ نظام تقييم الإستدامة البيئية للمباني بالمملكة البريطانية BREEAM (11) :}

(Building Research Establishments Environment Assessment Method) BREEAM يعتبر :

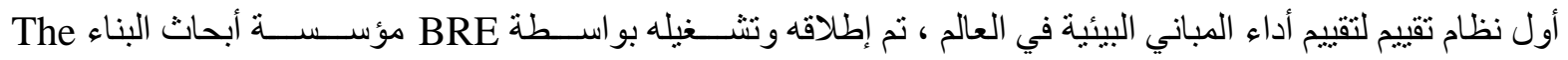
في المملكة المتحدة ، تم تقديمه إلى السـوق في عام 1990 وتم تنقيحه لأول 
مرة لتقييم المكاتب في عام 1993 ، يسـتخدم BREEAM على نطاق واســع بسـبـب مرونته كما أنه يهدف لتقييم المباني

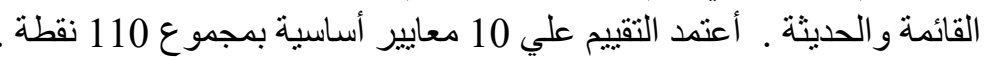

جدول 1 يوضح تحليل نظام BREEAM ، لعرض عناصر التقيبيم والأوزان النسبية لكل عنصر ، ثم حصر لنقاط التقييم الخاصة بالإنبعاثات.

\begin{tabular}{|c|c|c|c|c|c|}
\hline \multicolumn{3}{|c|}{ الأوزان النسبية لنقاط تقييم الإنبعاثات نظام BREEAM) } & \multicolumn{3}{|c|}{ عناصر التقييم والأوزان النسبية لنظام BREEAM } \\
\hline النقاط & نقاط تقييم الإنبعاثات & r & الوزن النسبي & عنصر التقييم & 5 \\
\hline 15 & معدل الإنبعاثات بالمبني & 1 & $\% 13$ & الإدارة & 1 \\
\hline 2 & مصدر الطاقة منخفض الإستهلاك للكربون & 2 & $\% 15$ & صحة الإنسان & 2 \\
\hline 2 & الكربون الوارد من المو اد & 3 & $\% 19$ & الطاقة & 3 \\
\hline 19 & المجموع & & $\% 7$ & النقل & 4 \\
\hline \multirow{7}{*}{\multicolumn{3}{|c|}{ مجموع نقاط تقييم الإنبعانات 19 نقطة من إجمالي 11 110 نقطة ، مما }} & $\% 7$ & 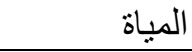 & 5 \\
\hline & & & $\% 9$ & 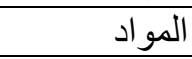 & 6 \\
\hline & & & $\% 5$ & المخلفات & 7 \\
\hline & & & $\% 8$ & الأبكولوجي & 8 \\
\hline & & & $\% 9$ & التلوث & 9 \\
\hline & & & $\% 8$ & الإبتكار & 10 \\
\hline & & & $\% 100$ & \multicolumn{2}{|c|}{ المجموع } \\
\hline
\end{tabular}

يلاحظ من خلال التحليل السابق إهتمام نظام BREEAM بالطاقة حيث منلت 19 \% من إجمالي التقييم ، و هذا بمثل خطوة

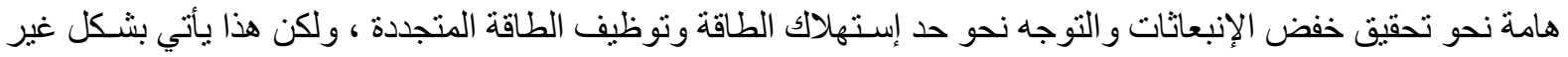

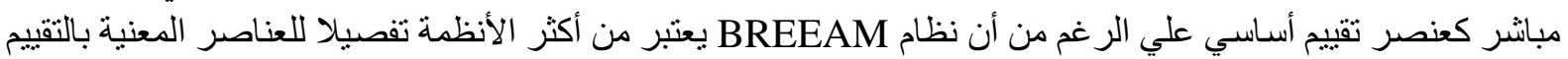
و وبالنظر الي الوزن النسبي لتقيبم الإنبعاثات من خلال النقاط المطروحة لنظام الـ BREEAM يتضح أنها مثلت 19 نقطة الـان.

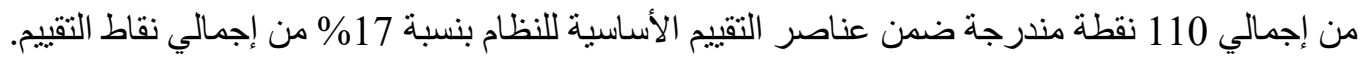

\section{ب- نظام تقييم المباني المستدامة بالولايات المتحدة LEED (9) :}

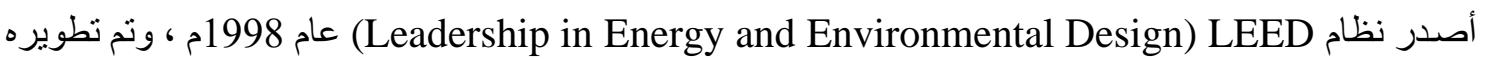
بو اسطة المجلس الأمريكي للبناء الأخضر USGBC ، وهو نظام معترف به دوليا كمقياس لتصميم و إنشاء وتشغيل المباني

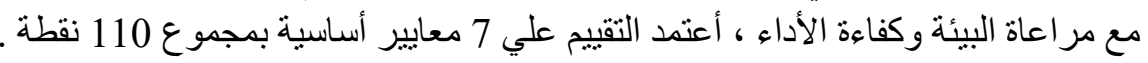

جدول 2 يوضح تحليل نظام LEED ، لعرض عناصر التقييم والأوزان النسبية لكل عنصر ، ثم حصر لنقاط التقييم الخاصة بالإنبعاثات

\begin{tabular}{|c|c|c|c|c|c|}
\hline \multicolumn{3}{|c|}{ الأوز ان النسبية لنقاط تقييم الإنبعاثات نظام (9)LEED) } & \multicolumn{3}{|c|}{ عناصر التقييم والأوزان النسبية لنظام LED } \\
\hline النقاط & نقاط تقييم الإنبعاثات & s & 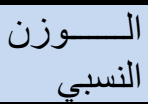 & عنصر التقييم & r \\
\hline 2 & والمواد منخفضــــــة الإنبعـات ــ المواد اللاصــــــة & 1 & $\% 24$ & إستدامة الموقع & 1 \\
\hline 2 & مو اد منخفضة الإنبعاث ـ دهانات وطلاءات & 2 & $\% 9$ & كفاءة المياة & 2 \\
\hline 2 & مو اد منخفضة الإنبعاثات ـ أنظمة السجاد & 3 & $\% 32$ & الطاقة والغلاف الخارجي & 3 \\
\hline 2 & والألياف الزفر اعية الإنبعاثات ــ الخشـــبـ المركب & 4 & $\% 13$ & المو اد ومصسادر الموارد & 4 \\
\hline 2 & التخلص من الغازات الناتجة عن الإحتر اق & 5 & $\% 13$ & جودة البيئة الداخلية & 5 \\
\hline 10 & \multicolumn{2}{|l|}{ المجموع } & $\% 5$ & عملية التصميم و الإدارة & 6 \\
\hline \multirow{2}{*}{\multicolumn{3}{|c|}{ مجموع نقاط تقييم الإنبعاثات 10 نقاط من إجمالي 110 نقطة ، مما }} & $\% 4$ & أخري & 7 \\
\hline & & & $\% 100$ & المجموع & 8 \\
\hline
\end{tabular}

من خلال التحليل الســابق يلاحظ إهتمام نظام LEED بالطاقة و الغلاف الخارجي حيث منلت 32 \% من إجمالي الوزن النسبي الكلي للتقييم ، في حين نأتي إستدامة الموقع بنسبة كبيرة 24 \% ، يأتي ذلك نتيجة دمج الكثير من نقاط التقيبم 
في معايير أقل مقارنة بنظام الــ BREEAM ، حيث يتم التقييم علي 6 معايير أساسية ومعيار أضافي تبعا لما يعمل عليه

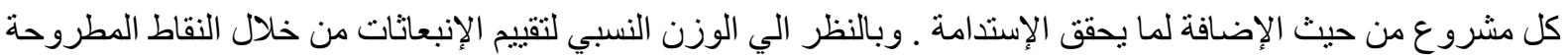
لنظام الـ LEED يتضح أنها مثلت 10 نقطة من إجمالي 110 نقطة مندرجة ضمن الإنة عناصر التقييم الأساسية للنظام بما يمثل نسبة 9\% من الوزن النسبي لإجمالي نقاط التقبيا .

تـ نظام تقييم المباني المستدامة باستراليا GREEN STAR (12) :

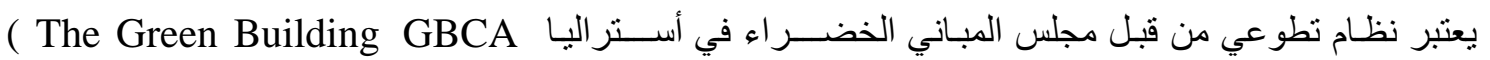
Council of Australia )

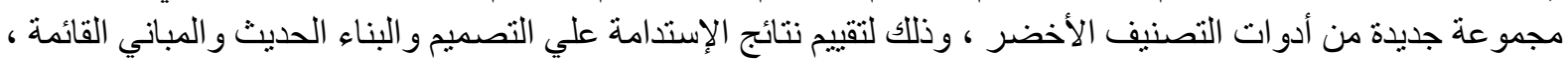
وتم تصنيفها الي 8 معايير أساسية بمجموع الفهات 100 نقطة .

جدول 3 يوضح نحليل نظام GREEN STAR ، لعرض عناصر التقييم والأوزان النسبية لكل عنصر ، ثم حصر لنقاط التقييم الخاصة بالإنبعاثات.

\begin{tabular}{|c|c|c|c|c|}
\hline \multicolumn{2}{|c|}{$\begin{array}{c}\text { الأوزان النسبية لنقاط تقييم الإنبعاثات نظام STAR } \\
\text { (12)STEEN }\end{array}$} & \multicolumn{3}{|c|}{$\begin{array}{c}\text { GREEN عناصر التقييم والأوزان النسبية لنظام } \\
\text { STAR }\end{array}$} \\
\hline عدد النقاط & م| نقاط تقييم الإنبعانات & 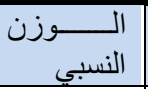 & عنصر التقييم & 5 \\
\hline 4 & 1 الحد من انبعاثات غاز ات الدفيئة ـ غلاف المبنى & $\% 9$ & 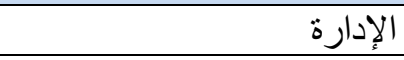 & 1 \\
\hline 2 & 2 تقليل انبعاثات غاز ات الدفيئة ـ تزجيج & $\% 20$ & جودة البيئة الداخلية & 2 \\
\hline 2 & 3] الحد من انبعاثات غاز ات الدفيئة ــ الإضـاءة & $\% 24$ & الطاقة & 3 \\
\hline 1 & 4 | تأثثير ات العدوي من أنظمة التبريد & $\% 7$ & النقل & 4 \\
\hline 9 & المجموع & $\% 12$ & 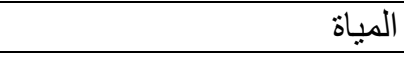 & 5 \\
\hline \multirow{4}{*}{\multicolumn{2}{|c|}{ مجموع نقاط تقييم الإنبعاثات 9 نقاط من إجمالي 100 نقطة ، مما }} & $\% 17$ & المو اد & 6 \\
\hline & & $\% 8$ & إستعمال الأرض و الإيكولوجي & 7 \\
\hline & & $\% 3$ & الإنبعاثات & 8 \\
\hline & & $\% 100$ & المجموع & \\
\hline
\end{tabular}

من خلال التحلبل السابث بلاحظ إهتمام أن نظام GREEN STAR بالطاقة ، حيث مثلت 24 \% من إجمالي الوزن

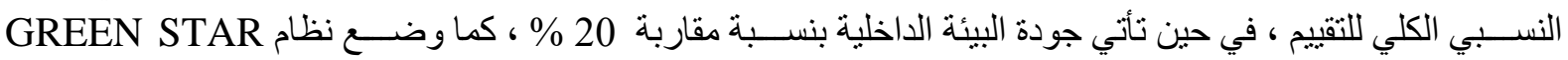

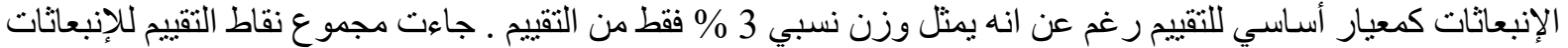

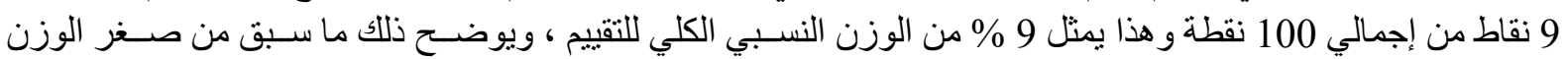

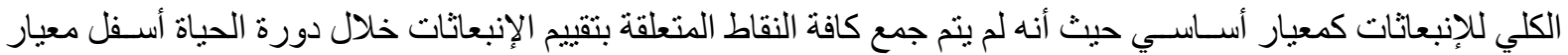

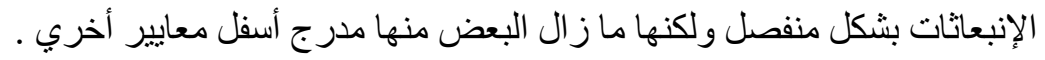

ثـ نظام تقييم المباني المستدامة بدولة الإمارات العربية المتحدة ESTIDAMA (10) :

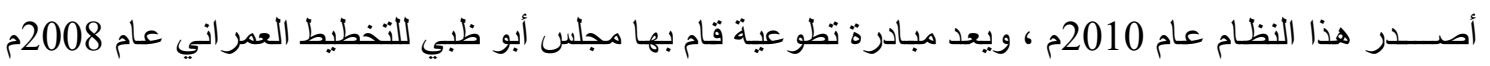
لتوجية رؤية أبو ظبي 2030م في إنثـاء مجتمعات عمر انية جديدة تقوم علي أسـاس الإسـتـامة ، يتم القياس من خلال هذا

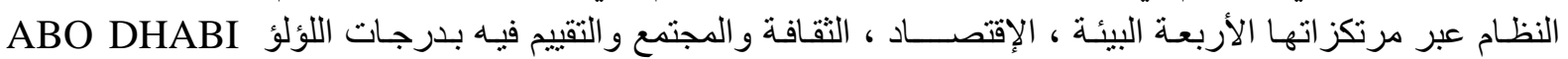

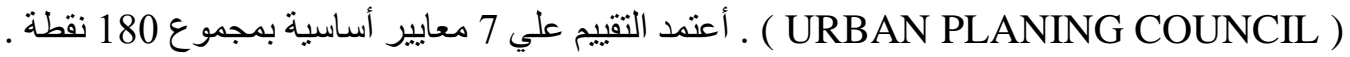


جدول 4 يوضح نحليل نظام ESTIDAMA ، لعرض عناصر التقييم والأوزان النسبية لكل عنصر ، ثم حصر لنقاط التقييم الخاصة بالإنبعاثات و وأوزانها النسبية.

\begin{tabular}{|c|c|c|c|c|c|}
\hline \multicolumn{3}{|c|}{ الأوز ان النسبية لنقاط تقييم الإنبعاثات نظام ESTIDAMA) } & \multicolumn{3}{|c|}{ عناصر التقييم و الأوزان النسبية لنظام STIDAMA } \\
\hline عدد النقاط & نقاط تقييم الإنبعاثات & م & 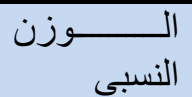 & عنصر التقييم & $s$ \\
\hline 1 & التبـربـاث المو اد : المواد اللاصــــة ومـانعـات & 1 & $\% 7,3$ & عملية التطوير المتكامل & 1 \\
\hline 1 & انبعاث المو اد : الدهان ومو اد التغليف & 2 & $\% 6.7$ & الأنظمة الطبيعية & 2 \\
\hline 1 & 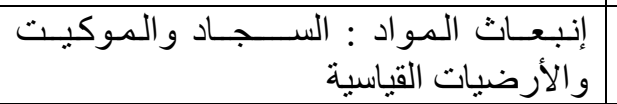 & 3 & $\% 21$ & المباني الملائمة للعيش & 3 \\
\hline 1 & إنبعاث المو اد : نظام السطح & 4 & $\% 24,2$ & مورد المباة & 4 \\
\hline 4 & أنثر المبردات وأجهزة إطفــاء الحريق في & 5 & $\% 24,8$ & 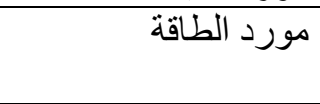 & 5 \\
\hline 8 & المجموع & & $\% 16$ & مو اد الإنشاء و البناء & 6 \\
\hline \multirow{2}{*}{\multicolumn{3}{|c|}{ مجموع نقاط تقييم الإنبعاثات 8 نقاط من إجمالي 180 نقطة ، وزن نسبي . }} & إضـافي & الإبتكار وتحسين الأداء & 7 \\
\hline & & & $\% 100$ & \multicolumn{2}{|c|}{ 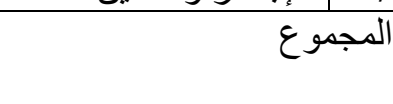 } \\
\hline
\end{tabular}

من خلال التحليل السابق لنظام ESTIDAMA يلاحظ تقارب الأوزان النسبية لنصف معايير التقييم الأساسية وهي

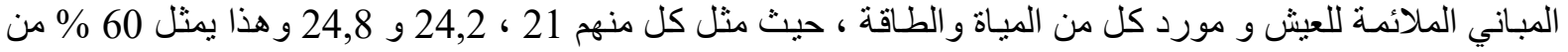

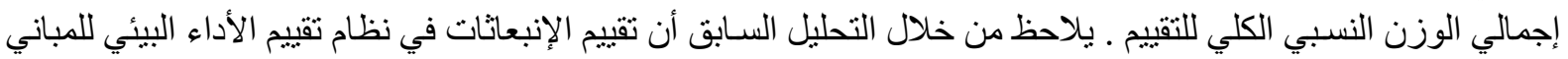
الــ ESTIDAMA مثلت وزن نسبي 4\% بعدد نقاط 8 نقاط من إجمالي 180 مندرجة ضـمن عناصر التقييم الأسـاسية

للنظام ، كما يتضح التركيز الأكثر علي تقييم المو اد و إختيار ها إلي جانب الأجهزة المستخدمة بالتبريد بإجمالي 4 نقاط

\section{نظام تقييم المباني المستدامة بجمهورية مصر العربية نظام الهرم الأخضر GPRS (15) :}

\section{ج}

تم إصدار هذا نظام الهرم الأخضر Establishment of Egyptian Green Building Council في مصند

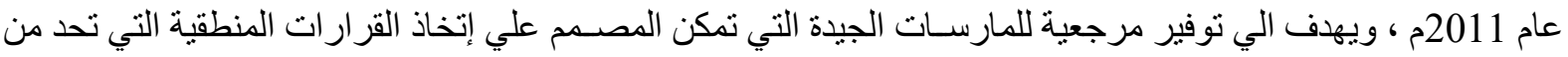

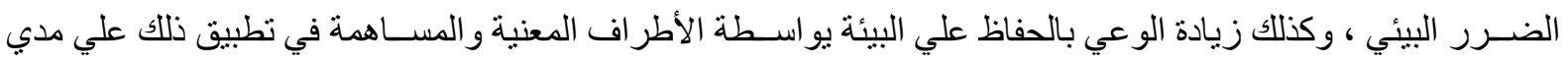

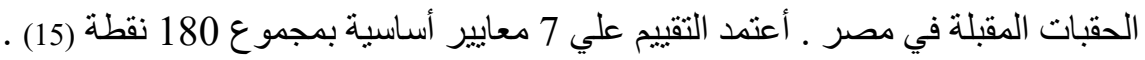

جدول 5 يوضح تحليل نظام GPRS ، لعرض عناصر التقييم والأوزان النسبية لكل عنصر ، ثم حصر لنقاط التقييم الخاصة بالإنبعاثات .

\begin{tabular}{|c|c|c|c|c|c|}
\hline \multicolumn{3}{|c|}{ (15) GPRS الأوزان النسبية لنقاط تقييم الإنبعاثات نظام } & \multicolumn{3}{|c|}{$\begin{array}{c}\text { عناصر التقييم والأوزان النسبية لنظام } \\
\text { GPRS }\end{array}$} \\
\hline عدد النقاط & نقاط تقييم الإنبعاثات & 5 & الوزن النسبي & عنصر التقييم & 5 \\
\hline 2 & مخزون الطاقة و الكربون & 1 & $\% 5$ & إستدامة الموقع & 1 \\
\hline 5 & التحكم في الإنبعاثات الناتجة عن مو اد البناء & 2 & $\% 25$ & كفاءة الطاقة & 2 \\
\hline 2 & التحكم في الإنبعاثات و الملوثات & 3 & $\% 35$ & كفاءة إستخدام المياة & 3 \\
\hline 9 & \multicolumn{2}{|c|}{ المجموع } & $\% 10$ & المو ادو الموارد & 4 \\
\hline \multirow{4}{*}{\multicolumn{3}{|c|}{ مجمو ع نقاط تقييم الإنبعاثات 9 نقاط من إجمالي 180 نقطة ، مـا }} & $\% 10$ & جودة البيئة الداخلية & 5 \\
\hline & & & $\% 10$ & الإدارة & 6 \\
\hline & & & $\% 5$ & الممارسات المبتكرة & 7 \\
\hline & & & $\% 100$ & rو عو ع & \\
\hline
\end{tabular}

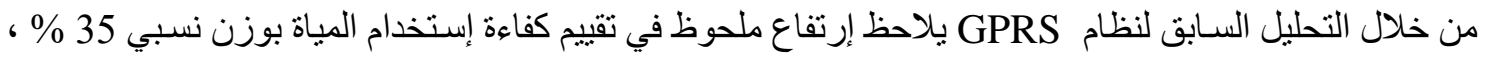
ثم تليها الطاقة بـ 25\% ، وينعكس هذا نتيجة إهتمام الدولة بترشيد المياة كهدف أساسي للتنمية المحلية خلال الأونة الأخيرة 
، ثم جاءت باقي المعايير بنسب متفاوتة فيما بينها تبعا لنقاط تقييمها .كما يلاحظ من خلال التحليل السابق أن تقييم الإنبعاثات

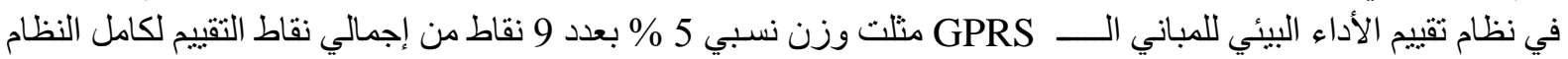

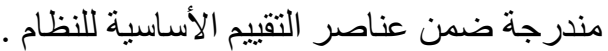

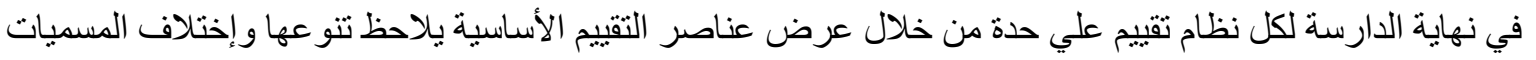

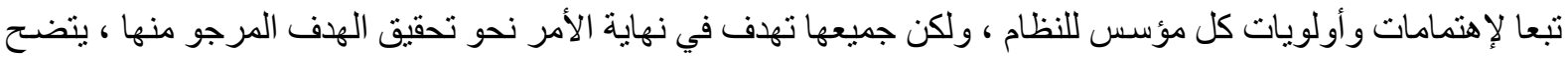

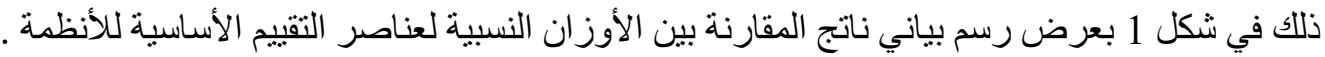

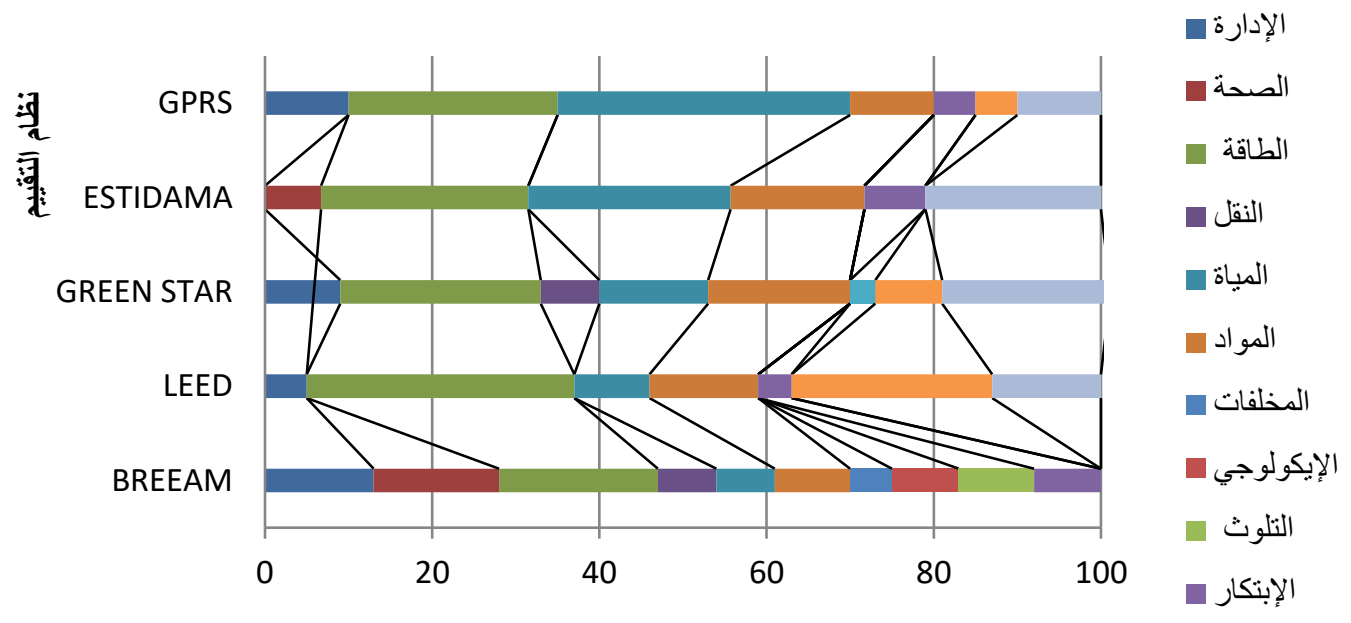

شكل 1 رسم بياني للمقارنة بين الأوزان النسبية لعناصر التقييم الأساسية للأنظمة محل الدراسة ( الباحثة ) .

• تقدم نظام BREEAM في كل من الإدارة والإبتكار هذا الي جانب إفنر ادها بعناصر تقييم خاصـة بها كصحة الإنسـان ،

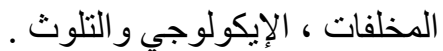

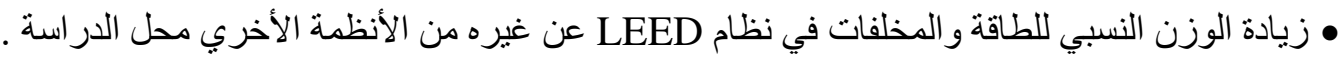
• إنفر اد نظام GREEN STAR بمعيار الإنبعانات دون عن الأنظمة الأخري ، الي جانب زيادة الوزن الأنس النسـبـي للطاقة و والمواد . • تقدم نظام GPRS بمعيار المياة ثم جاءت الطاقة بعدها في الوزن النسبي . 


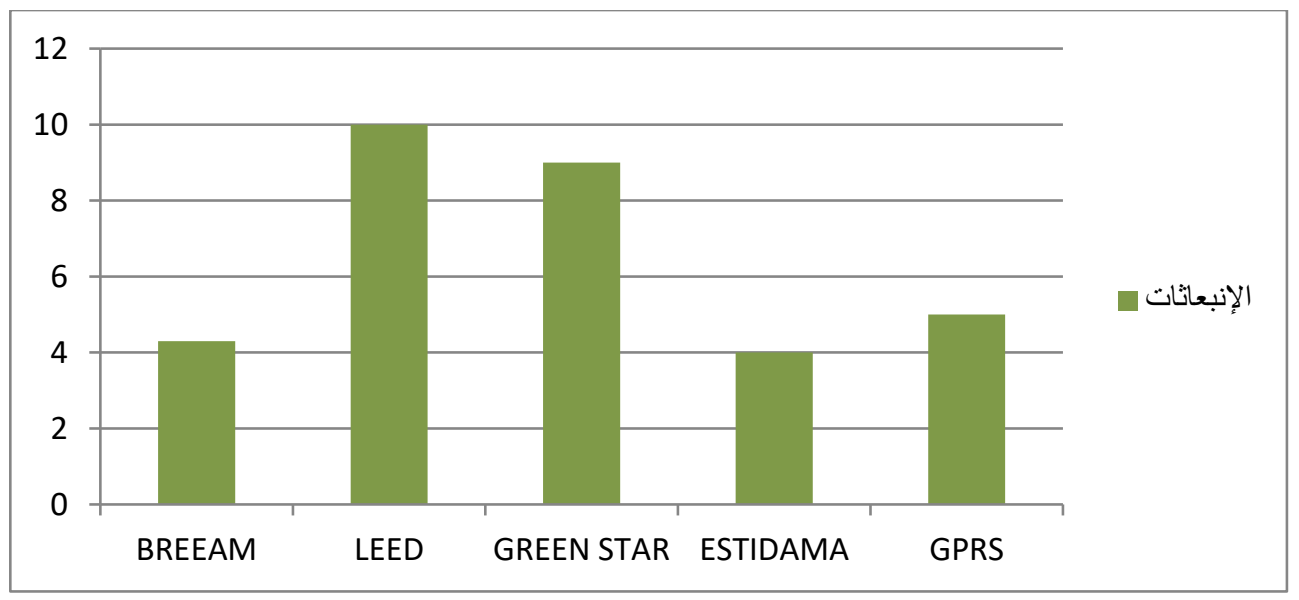

شكل 2 رسم بياني للمقارنة بين الأوزان النسبية لنقاط تقييم الإنبعاثات الكربونية للانظمة محل الدراسة ( الباحثة )

\section{8- التحليل الكمي للفئات المشتركة بين أنظمة التقييم :}

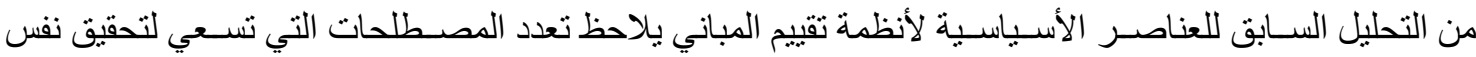
الهدف البيئي ، والتي من الممكن دمجها معا في عناصر رئيسية مشتركة بين الأنظمة الخمس ، ويمكن تحديدها كالتالي :

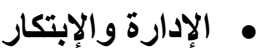
• • الموقع : تشمل الموقع و إستعمال الأراضي و النقل و المياة .

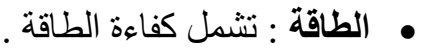

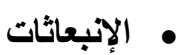
• الصحة والجودة : تشمل راحة المستعمل ، جودة الفر اغات وصحة الإنسان .

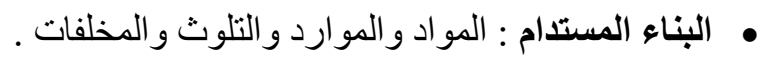

\begin{tabular}{|c|c|c|c|c|c|}
\hline GPRS & ESTIDAMA & $\begin{array}{c}\text { GREEN } \\
\text { STAR }\end{array}$ & LEED & BREEAM & الرئيسيــــر \\
\hline$\% 15$ & $\% 7.3$ & $\% 9$ & $\% 9$ & $\% 21$ & الإدارة \\
\hline$\% 40$ & $\% 30.9$ & $\% 27$ & $\% 33$ & $\% 22$ & الموقع \\
\hline$\% 25$ & $\% 24.8$ & $\% 24$ & $\% 32$ & $\% 19$ & الطاقة \\
\hline- & - & $\% 3$ & - & - & الإنبعاثات \\
\hline$\% 10$ & $\% 21$ & $\% 20$ & $\% 13$ & $\% 15$ & والـودةد الصـــة \\
\hline$\% 10$ & $\% 16$ & $\% 17$ & $\% 13$ & $\% 23$ & الـــــــــــــاء \\
\hline
\end{tabular}




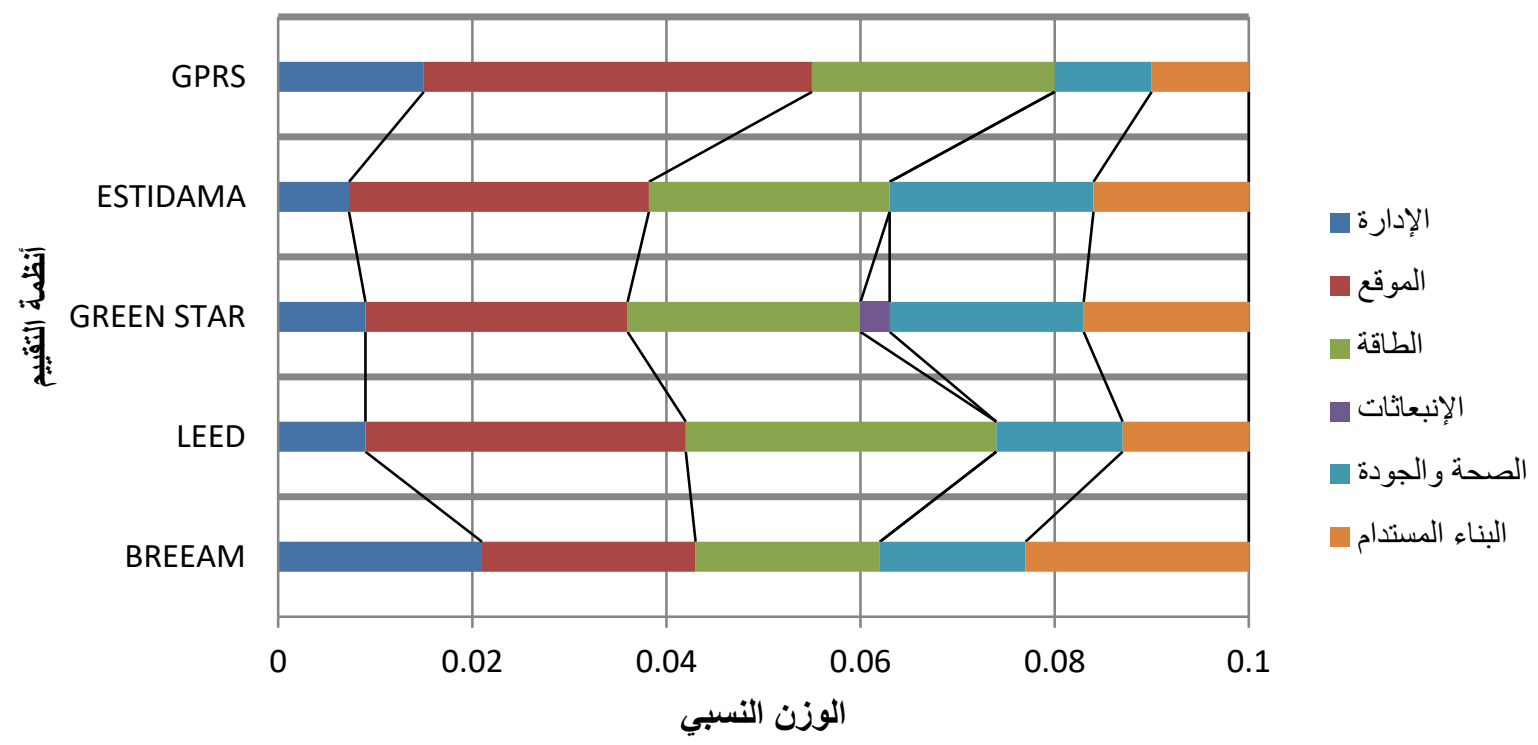

شكل 3 رسم بياني للمقارنة بين الأوزان النسبية لعناصر التقييم بعد دمجها تبعا لفئات تقييم مشتركة ( الباحثة ) .

بعد دمج معايير التقييم و التوصل الي معايير مشتركة مع الحفاظ علي الإنبعانات كمعيار أساسي ، لاحظ الأتى :

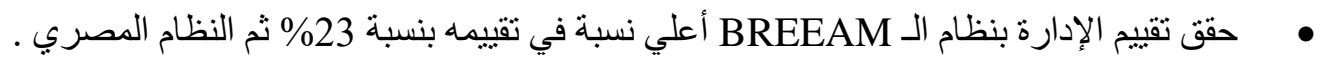

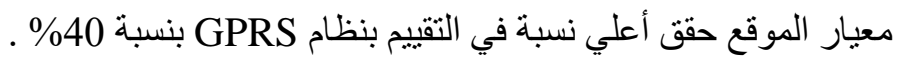
نظام GREEN STAR هي النظام الوحيد الذي حقق إعتبار الإنبعاثات كعنصر أساسي .

يبــتنج مما ســـق أن نظام التقييم الأســتر الي GREEN STAR يمكن إعتباره أكثر نظم إهتماما بتقبيم الإنبعانات الكربونية وذللك بوضعها كعنصر تقييم أساسي.

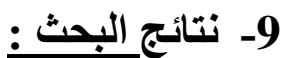

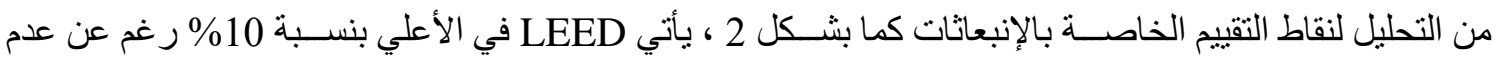

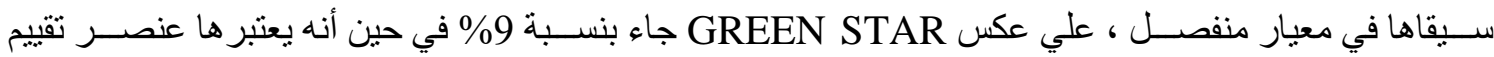
أتفقت نقاط تقييم الإنبعانات الكربونية علي إســتهداف مو اد البناء خلال مر احل دورة لحياة ، ثم الأجهزة المســتخدمة

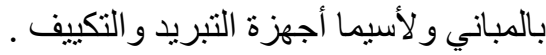
يعتبر نظام GREEN STAR شامل لكافة معايير التقييم المستهدفة للتنمبة المستدامة ، و أهمها إعطاء مؤشر لتقيبيم الإنبعاثات الكربونية كمعيار مستقل .

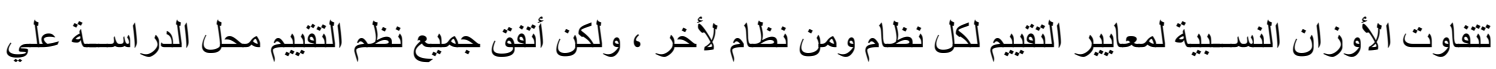
تقل الوزن النسـبـي لكل من معيار الطاقة ، و الموقع وكذلك معيار جودة الفر اغات الداخلية رغما عن تفاوت من نظام

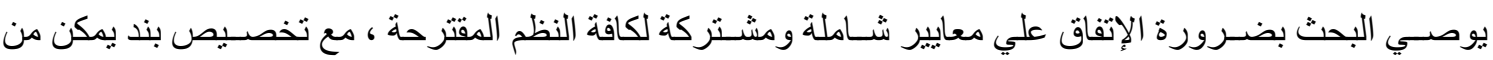

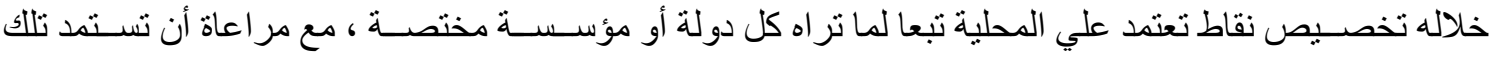

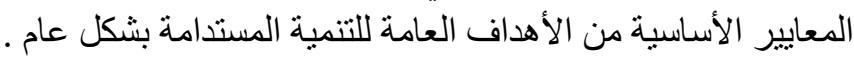

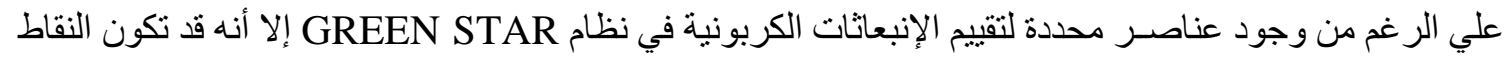

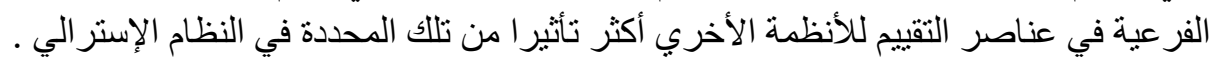


يوصـي البحث بضـرورة إعادة سـياق نقاط التقييم للنظام الأسـتر الي GREEN STAR فيما يخص النقاط الخاصـة

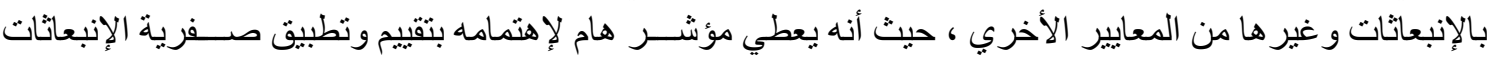

(1) Chau C, Leung T, Ng W. A review on life cycle assessment, life cycle energy assessment and life cycle carbon emissions assessment on buildings. Appl Energy 2015, 143

(2) Chong WKO, Kwok KYG, Ariaratnam ST, Kim J. Structuring a comprehensive carbon-emission framework for the whole lifecycle of building, operation, and construction. J Archit Eng 2016.

(3) Erhorn-Kluttig, H. and Erhorn, H.: Terms and definitions used in the EU Member States for High Performance Buildings (2009). Information Paper soon available on the EU portal BUILD UP.

(4) Guggemos AA, Horvath A, Comparison of environmental effects of steel-and concrete-framed buildings. J Infrastruct System 2005;-101.

(5) Gong Y, Song D, Life cycle building carbon emissions assessment and driving factors decomposition analysis based on LMDI, a case study of Wuhan City in China, Sustainability 2015 $-86$.

(6) Hetherington et al, Zero and low carbon buildings: A driver for change in working practices and the use of computer modelling and visualization, In: 14th International Conference on Information Visualization, 27-29 July 2010, London South Bank University, London, UK. P3 .

(7) Marszal AJ, Heiselberg P, Bourrelle JS, Musall E, Voss K, Sartori I, et al. Zero energy building-a review of definitions and calculation methodologies. Energy Build 2011, 9.

(8) Riedy , C. , Lederwasch , A. \& Ison , N. , Defining Zero emission building, review and recommendations : final report, Institute for Sustainable Future .

(9) Krishnan Gowrie Member ASHARAE, Green Building Rating System, ASHARAE Journal, 2004.

(10) ABO DHABI URBAN PLANING COUNCIL, ESTIDAMA: The Pearl Rating System: Design \& Construction, Version 0.1, 2010, http//www.estidama.com , 25-6-2021 .

(11) BRE Global, "BREEAM Multiresidential Assessor Manuals :Technical Guidance Document", 2018, http://www.breeam.org , 2020.

(12) Green Building Council Australia: About GBCA, (2017). http://www.gbca.org.au/about

(13) Jinkim , J \&Rigdon, Sustainable Architecture module : Qualities, Use, and Examples of Sustainable building Material, 2002 , WWW.umich.edu , 2020 .

(14) IEA, World Energy Balances, 2017, http://www.iea.org/publications/freepublications/WorldEnergybalances2017overview.pdf accessed on 6-2021

المركز القومي لبحوث البناء والإسكان ، المجلس المصري للأبنية الخضر اء ، نظام تصنيف المباني الهرم الأخضر ، 2015 